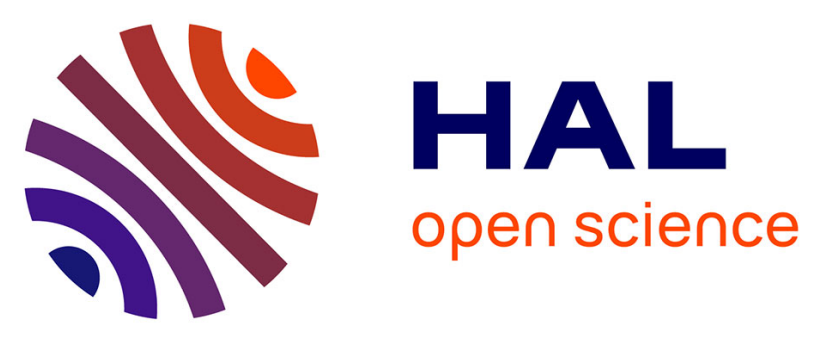

\title{
T.E.M. STUDY OF THE TEXTURE AND PREFERENTIAL ORIENTATION OF GRAIN BOUNDARIES IN POLYCRYSTALLINE NiO PREPARED BY METAL OXIDATION
}

M. Dechamps, A. Marrouche, Franck Barbier, A. Revcolevschi

\section{To cite this version:}

M. Dechamps, A. Marrouche, Franck Barbier, A. Revcolevschi. T.E.M. STUDY OF THE TEXTURE AND PREFERENTIAL ORIENTATION OF GRAIN BOUNDARIES IN POLYCRYSTALLINE NiO PREPARED BY METAL OXIDATION. Journal de Physique Colloques, 1985, 46 (C4), pp.C4-435C4-440. 10.1051/jphyscol:1985448 . jpa-00224699

HAL Id: jpa-00224699 https://hal.science/jpa-00224699

Submitted on 1 Jan 1985

HAL is a multi-disciplinary open access archive for the deposit and dissemination of scientific research documents, whether they are published or not. The documents may come from teaching and research institutions in France or abroad, or from public or private research centers.
L'archive ouverte pluridisciplinaire HAL, est destinée au dépôt et à la diffusion de documents scientifiques de niveau recherche, publiés ou non, émanant des établissements d'enseignement et de recherche français ou étrangers, des laboratoires publics ou privés. 
JOURNAL DE PHYSIQUE

Colloque C4, supplément au $n^{\circ} 4$, Tome 46, avril 1985

page $\mathrm{C} 4-435$

\title{
T,E,M. STUDY OF THE TEXTURE AND PREFERENTIAL ORIENTATION OF GRAIN BOUNDARIES IN POLYCRYSTALLINE NIO PREPARED BY METAL OXIDATION
}

\author{
M. Dechamps, A. Marrouche, F. Barbier and A. Revcolevschi \\ Laboratoire de Chimie Appliquée, Université Paris-Sud, 91405 Orsay Cedex, \\ France
}

Résumé - On a dēterminé par diffraction électronique les relations d'orientation, 1 'indice de coīncidence et le plan du joint de grains de 71 couples de cristaux adjacents dans de l'oxyde de nickel polycristallin.

Abstract - Orientation relations, coincidence index and Miller indices of grain boundary planes were determined by electron diffraction for 71 couples of adjacent crystals in polycrystalline NiO prepared by oxidation of $\mathrm{Ni}$.

\section{INTRODUCTION}

Atkinson and Taylor, and Chen and Peterson have observed a significant intergranular diffusion in nickel oxide. The intergranular diffusion coefficients of $\mathrm{Ni}$ and $\mathrm{Co}$ in polycrystalline NiO prepared by oxidizing a foil of high purity nickel $25 \mu \mathrm{m}$ in thickness at $1100^{\circ} \mathrm{C}$ have been determined by Atkinson and Taylor /1/ whereas Chen and Peterson have determined the intergranular diffusion coefficients of $\mathrm{Co}$ and $\mathrm{Cr}$ in polycrystalline $\mathrm{NiO}$ grown from the melt by the flame fusion technique /2/. The results indicate a significant quantitative disagreement between the diffusion data relative to co but, so far, no convincing reasons were found to explain it.

In order to clarify this discrepancy one of us ( $F$. Barbier) has carried out experiments in which cobalt was diffused into bicrystalline NiO samples of known misorientation. Several bicrystals having a <001> or $4011>$ symmetrical tilt axis were grown by the flame fusion technique $/ 3 /$, then submitted to various thermal treatments in order to promote intergranular diffusion of Co. No preferential diffusion of cobalt at the grain boundaries has been observed. These results led us to characterize with more precision the nickel oxide which was used by Atkinson and Taylor and the bicrystalline samples used in our laboratory, in order to explain the different behaviour of the two materials. We present here the results of a T.E.M. characterization of the polycrystalline grain boundaries, our purpose being the determination of the orientation relationships existing between adjacent crystals and the precise crystallographic characterization of the grain boundaries (G.B.). Other data obtained during this study are presented, concerning, in particular, the oxidation texture of the polycrystalline samples.

\section{I - METHOD OF CHARACTERIZATION AND RESULTS}

\section{Specimen preparation}

Ni0 polycrystalline samples were provided by Atkinson after being prepared by the procedure described in $/ 1 /$. Taking into account the observations of Atkinson and Taylor, $3 \mathrm{~mm}$ NiO disks were polished on both faces then ion-milled for electron transparency. Various areas in each sample were examined yielding a total of 71 grain boundary characterizations. No significant difference between the various samples or between different areas of one sample was noticed, which seems to indicate that our results are representative of the NiO polycrystalline samples. 


\section{Orientation relationships}

In order to determine by T.E.M. the orientation relationships existing between any two adjacent crystals we have used the numerical method proposed by Fontaine and Rocher $/ 4 /$, which is only slightly different from that proposed by Karakostas et al $15 /$, both techniques using the matrix formalism developed by Lange /6/. Basically the method consists of characterizing each crystal by 3 non coplanar crystallographic directions which define the transformation matrix $M_{1}$ from the $<001>$ orthonormal trihedron to the experimental crystalline trihedron. Simultaneously the 3 corresponding pairs of angles $\alpha$ and $\beta$ read on the goniometer stage of the microscope give access to the spherical coordinates of each experimental direction in a fixed orthonormal trihedron, i.e. to the transformation matrix $M_{2}$ from the fixed trihedron to the experimental trihedron. Hence the matrix product $\sigma=\left(M_{2} t\right)^{-1} \cdot M_{1} t$, where the exponent $t$ stands for transposed matrix, defines the transformation matrix from the fixed orthonormal trihedron to the crystal $<001>$ trihedron.

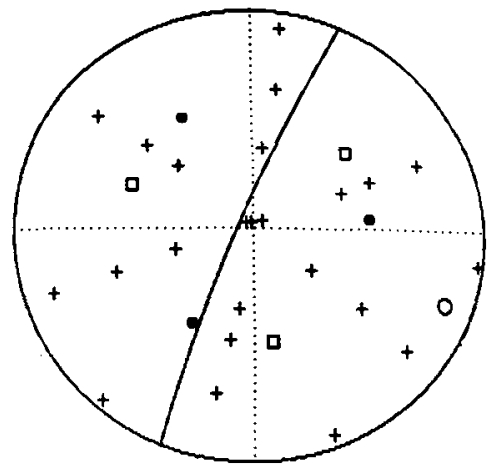

Fig. 1 - Stereographic projection of a $\Sigma=7$ bicrystal with the plane of the thin foil 1 as the plane of projection.

$\square<001>$ directions of crystal 1 .

- $\langle 001\rangle$ directions of crystal 2 .

+ directions of the 24 possible axes of rotation.

o pole of the G.B. plane. The G.B. is represented by a solid line meridian.

If $\sigma^{\prime}$ is the equivalent matrix for a second crystal, then the rotation matrix between both crystals is $R=\sigma^{\prime} t . \sigma$. The rotation angle is calculated from the trace of $R$ and the rotation axis is an Eigen vector of $R$. The 24 equivalent descriptions associated with cubic symmetry may be obtained by permutation of the elements of $\sigma^{\prime}$, $\sigma$ remaining unchanged. As an example, the graphical expression of one calculation is represented in $\mathrm{fig} .1$.

\section{Coincidence indices}

The previous results were used to investigate the possible existence of a coincidence index $\Sigma^{*}$ for each couple of adjacent crystals. Two methods were used. First $\Sigma$ was computed by trial and error using the relation $Y / X=\operatorname{tg}(\theta / 2) / \sqrt{N}$, where $N=h^{2}+k^{2}+1^{2}$ and $\Sigma=X^{2}+N \cdot Y^{2}$ ( $Y$ and $X$ are integers relatively prime; $\theta$ is the misorientation angle and $h$ k 1 are integer indices of the misorientation axis) which was shown to be valid, if $\theta \neq 180^{\circ}$, only if both crystals are coincident $/ 7,8 /$. If $\theta=180^{\circ}$, then $\Sigma=h^{2}+k^{2}+l^{2}$. Secondly, $\Sigma$ was also found by direct comparison with the coincidence tables established by Mykura /9/ or others/e.g. 10/. But before assigning a bicrystal a $\Sigma$ value two problems had to be solved. The first is the choice of the upper limit physically meaningful for $\Sigma$. The second is the definition of the angular interval $\Delta \theta$ allowed from the strict coincidence misorientation $\theta$. Concerning the upper

* $\Sigma$ is defined as the ratio of the volume of the coincidence site lattice unit cell to that of the crystal lattice unit cell. 


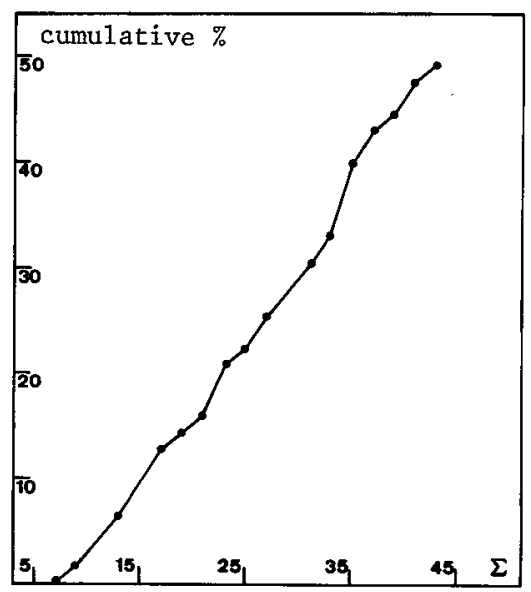

Fig. 2 - Cumulative frequency of bicrystals characterized by a coincidence index, versus $\Sigma$. About $50 \%$ of the bicrystals analyzed fitted with an index $\Sigma \leqslant 41$, within the limits of Brandon's criterion. Within this population there is no noticeable preferential orientation relationship.

1 imit of $\Sigma$, it is impossible to define a precise value because of the lack of experimental or theoretical grounds. So far we have limited our investigation, for most of the samples, to $\Sigma \leqslant 41$, mainly because, up to now, secondary dislocation arrays have been observed up to $\Sigma=41$ in some materials /11/. However it must be noted that several bicrystals fit very well with larger values of $\Sigma$. As for the interval $\Delta \theta$, various semi-empirical criteria have been proposed, which are all formulated as $\Delta \theta=$ $\theta_{0} / \Sigma^{n}$ with $\theta_{0}=15^{\circ}$ or $8^{\circ}$ and $n=1$ or $0.5 / 12-14 /$. Following Warrington $/ 13 /$ we have chosen to apply the Brandon criterion $\Delta \theta=15 / \sqrt{\Sigma} / 13 /$. Fig. 2 presents our results in terms of cumulative frequency of the number of bicrystals versus $\Sigma$, in order to make easier a comparison with further results.

\section{Grain boundary plane}

Each boundary was indexed using several micrographs taken at various $\Omega$ tilt angles measured along the meridian perpendicular to the meridian representing the G.B. plane.

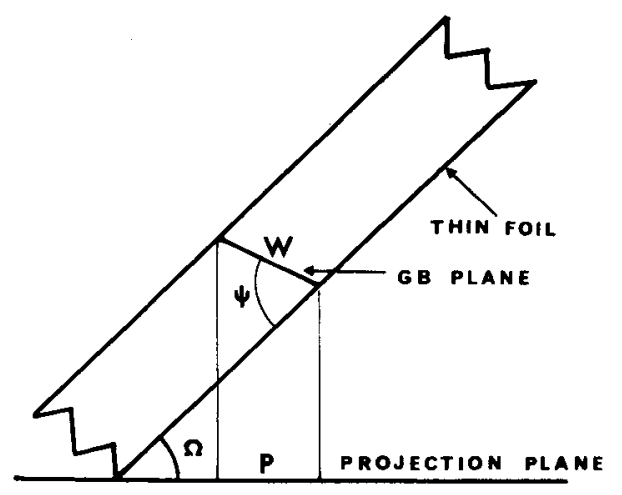

Fig. 3 - Schematic diagram of a thin foil section containing a grain boundary :

$W$ : actual width of the G.B.

$P$ : projected width of the G.B. on a horizontal plane.

$\Omega$ : angle between the horizontal plane and the foil plane.

$\Psi$ : angle between the foil plane and the G.B. plane. 


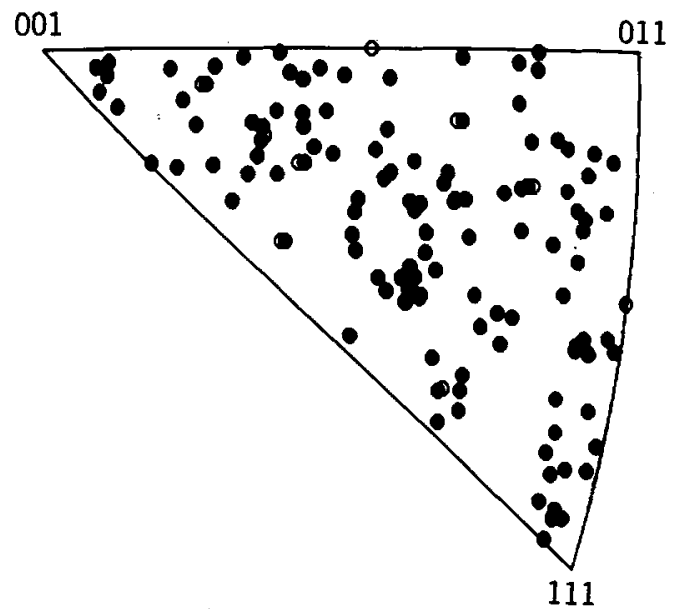

Fig. 4 - Distribution of the G.B. planes in a standard stereographic triangle. There is no G.B. plane with a pole close to [011]; the density of G.B. planes along the $011 / 111$ meridian is rather poorer than elsewhere, except near the 111 pole.

Its pole, in fig. 1 , is at the end of the meridian representing the G.B. plane; this pole corresponds to the fixed horizontal direction defined by the intersection of the G.B. plane and the foil plane when the latter is horizontal. In such a manner the dihedral angles $\Omega$ and $\Psi$ defined in fig. 3 Tie in the same plane and the relation between the actual width $W$ of the G.B. plane and its projection $P$ is obvious. It is of particular interest to formulate this relation as $P / \cos \Omega=a \cdot \operatorname{tg} \Omega+b$, where $a=$ - W. $\sin \Psi$ and $b=W \cdot \cos \psi$ are constants, because this linear relation lends itself very well to a linear regression. Although this method needs at least 3 or 4 micrographs, to be valid, it is more accurate (within one degree) than that proposed by Michaut /15/ or than the purely graphical ones.

Fig. 4 represents the graphical distribution of the G.B.'s. It is obvious that there is no marked preferential orientation except for the fact that there is no $G . B$. close to $\{011\}$ planes. One may also note a rather poor density of $\{11 \ell\}$ G.B. planes

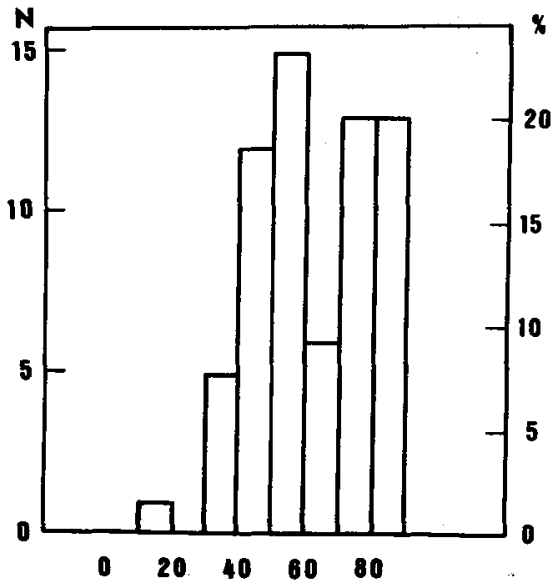

Fig. 5 - Statistical orientation of the G.B. planes with respect to the foil plane. Two groups of G.B. planes appear : the first is roughly perpendicular to the foil surface. The second is ti]ted approximately $50^{\circ}$. 
between the 001 and 111 poles. This area of the standard triangle corresponds partially to the symmetrical <011> tilt boundaries for which, as mentioned earlier, no preferential diffusion was observed so far.

Another important feature of the boundaries appears in fig. 5 where the G.B.'s frequency is plotted as a function of the angle formed by the G.B. plane and the surface of the thin foil assumed to be parallel to the initial $\mathrm{Ni}$ sheet. As expected the G.B.'s in the oxidized layer are strongly oriented and nearly half of them are closely perpendicular to the surface. However we observe a puzzling gap between this 1st group and a 2nd group for which the average angle with the surface is about $50^{\circ}$. We have so far no definitive explanation for the existence of such a gap.

\section{Texture}

Although electron diffraction is not really well suited for a texture study, some results are presented here since the data which were collected were in sufficient number to get some evidence of a marked crystalline growth texture, upon oxidation, along the approximate $\langle 111\rangle,\langle 123\rangle$ and $\langle 011\rangle$ directions (fig. 6 ).

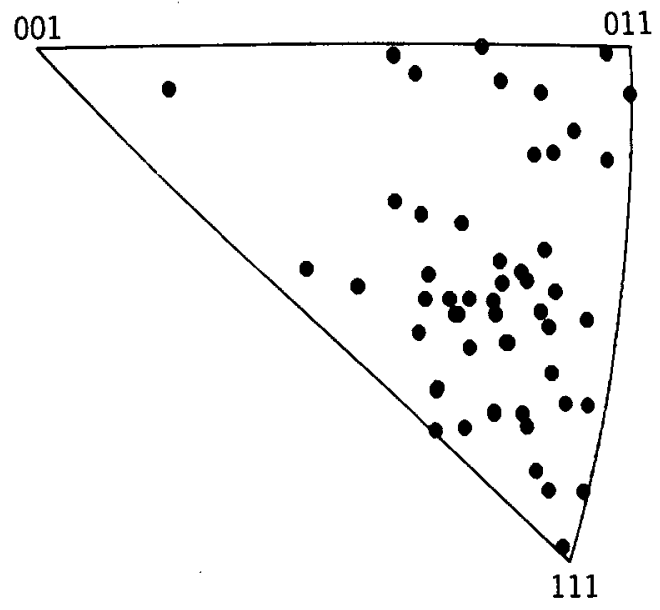

Fig. 6 - Distribution of the foil normals when indexed in relation to each grain. The oxidized specimen is strongly textured.

\section{CONCLUSIONS}

It appears that despite the existence of an oxidation texture, the crystallographic orientation of the nickel oxide G.B. planes in samples prepared by oxidation of nickel sheets is random, except in the 011 area where thev are lacking. Moreover, nearly all the G.B. planes are tilted more than $45^{\circ}$ with respect to the surface. Lastly, although a major fraction of the paired crystals can be characterized with a coincidence index, no intergranular preferential orientation relationships were observed. Obviously these results do not allow the prediction of atomic G.B. structures which could explain diffusion properties. They show however that, a priori, these oxidized specimens are very well suited to obtain information on the average intergranular diffusion since there is almost no preferential crystallographic orientation of the G.B. planes. Morevover these G.B.'s are well oriented with respect to the surface to carry out intergranular diffusion experiments. Nevertheless, we shall note that the G.B.'s of our bicrystalline samples are also well oriented for diffusion experiments but have another diffusional behaviour. One possible cause of this discrepancy is the preparation method of our bicrystals which might induce a facetting of the boundaries. 


\section{REFERENCES}

1 - ATKINSON A. and TAYLOR R.I., PhiT. Mag. A 43(1981)979. ATKINSON A. and TAYLOR R.I., PhiT. Mag. A 45(1982)583.

2 - CHEN W.K. and PETERSON N.L., J. Amer. SOc. $63(1980) 566$.

3 - DHALENNE G., REVCOLEVSCHI A. and GERVAIS A. . J. Crystai Growth $44(1978) 297$.

4 - FONTAINE C. and ROCHER A., J. MicrosC. Electron. 4(1979)19.

5 - KARAKOSTAS T., NOUET G., BLERIS G.L., hAgEgE S. añd DELAVIGNETTE P., Phys. Stat. Sol. (a) $50(1978) 703$.

6 - LANGE F.F., Acta Meta11. 15(1966)311.

7 - RANGANATHAN S., Acta Cryst. $21(1966) 197$.

8 - WOIRGARD J. and de FOUQUET J., Scripta Meta11. 6(1972)21.

9 - MYKURA H., Grain Boundary, Structure and kinetics, A.S.M. Materials Sc. Seminar Milwaukee (1979) 445 .

10 - BLERIS G.L. and DELAVIGNETTE P., Acta Cryst. A $37(1981) 779$.

11 - PENISSON J.M., d'ANTERROCHES C., DESSEAUX-THIBAULT J., BOURRET A. and RENAULT A., J. Microsc. Electron. 9(1983) 125.

12 - BRANDON D.G., Acta Metāi 1. 14(1966)1479.

13 - WARRINGTON D.H. and BOON M., Acta Meta17. 23(1975)599.

14 - ISHIDA Y. and MCLEAN M., PhiT. Mag. 27(1973)1125.

15 - MICHAUT B., Thèse d'Etat, Grenoble (1971). 